\title{
Drying Kinetics of Tomato, Okra, Potato and Mango in a Forced-Convective Solar Tunnel Dryer
}

\author{
Moussa Na Abou Mamouda ${ }^{1,2}$, Madougou Saïdou ${ }^{2}$, Boukar Makinta ${ }^{2}$ \\ ${ }^{1}$ Energy-Environment Development (ENDA Energy, Niger), Niamey, Niger \\ ${ }^{2}$ Laboratory of Energetics, Electronics, Electro Technics, Automatics and Industrial Computer Sciences, Abdou Moumouni University, \\ Niamey, Niger
}

\section{Email address:}

mamoudam@gmail.com (M. Na A. Mamouda)

\section{To cite this article:}

Moussa Na Abou Mamouda, Madougou Saïdou, Boukar Makinta. Drying Kinetics of Tomato, Okra, Potato and Mango in a ForcedConvective Solar Tunnel Dryer. International Journal of Sustainable and Green Energy. Vol. 8, No. 2, 2019, pp. 34-44.

doi: $10.11648 /$ j.ijrse.20190802.12

Received: May 23, 2019; Accepted: June 26, 2019; Published: July 8, 2019

\begin{abstract}
The design of a solar drier requires detailed information about drying kinetics of the products to be dried. The objective of our work is to characterize drying kinetics of tomato, okra, potato and mango and calculate the main drying parameters namely the drying rate, the moisture ratio and the effective diffusivity from the derivative form of the Fick's second law of diffusion. We found that solar drying of tomato, okra, potato and mango occur in both constant and falling-rate phases. Sound experimental conditions and specifically continuous measurements and data collection during experiments, emerged as a major factor allowing the observation of both a constant-rate and falling-rate phases. Two models namely the Henderson \& Pabis Model and the Page Model were used to characterize the evolution of moisture ratios $(M R)$ over time. For each of the abovementioned crops, the Page Model appeared to give a better description of $M R=f(t)$ with $\chi^{2}$ varying from 0.0051 to 0.0978. As per the Effective Moisture Diffusivity, its values were $8.866 \times 10^{-09}, 4.651 \times 10^{-09}, 4.969 \times 10^{-09}$ and $5.177 \times 10^{-09}$ for mango, tomato, potato and okra respectively. Calculated drying constants were compared with the ones obtained by other authors in similar experimental conditions. The experimental dryer we used was a forced convective solar tunnel dryer. All experimentations were conducted in Niamey (Niger) from 7 to 9 June 2018, 3 to 4 Mars 2019, 24 to 26 April 2018 and 1 to 3 May 2018 for mango, tomato, potato and okra respectively.
\end{abstract}

Keywords: Solar Dryer, Mango, Okra, Tomato, Potato, Drying Kinetics, Niger

\section{Introduction}

The production of fruits and vegetables offers reliable potential for food security and poverty alleviation in rural areas of Niger. During the dry season, these fruits and vegetables are produced in massive quantities. Selling prices are therefore so low that farmers' earnings are hardly sufficient to allow another production next year. In the absence of options for transformation and conservation, these fruits and vegetables can decay and quickly become rare in markets, resulting to a tremendous increase of their prices in lean periods.

Drying is the most common preservation technique used to extend the shelf-life of fresh vegetables and fruits as well as to facilitate their transportation and storage $[1,2]$.

Traditionally, farmers in Niger adopt the process of drying in order to reduce post harvest losses. Niger is a country where dried fruits and vegetables are already strongly part of the culinary habits of people. However, drying of these fruits and vegetables often takes place in a rudimentary manner, on the ground, which makes the dried products contaminated by dust, sand, dead insects, animal defecation, mould spores, etc. and therefore unsuitable for consumption. Losses of food quality in inadequately dried products may have adverse economic effects on domestic and international markets [3, 4].

Solar tunnel dryer reduces crop losses, improve the quality of dried product significantly and is economically beneficial compared to traditional drying methods [5].

In order to address food losses and reduce market instability, designing and sizing of adequate solar dryer for drying of fruits and vegetables, particularly tomato, okra, 
potato and mango, is of utmost importance. Solar dryers must be properly designed in order to meet particular drying requirements of agricultural products and give satisfactory performance concerning energy requirements [5].

The achievement of such objective specifically requires a comprehensive assessment of the drying parameters and constants involved in the drying kinetics of the crops to be dried. Our work consisted in conducting several drying experiments to investigate the thin-layer drying kinetics of tomato, okra, potato and mango in a solar tunnel dryer. Simulation models as a valuable tool for prediction of performance of solar drying systems [6] were used to determine key drying constants. The review of existing literature on drying experiments has shown significant divergences among authors on the existence or not of a constant-rate alongside with a falling-rate phase over the drying process of fruits and vegetables. This study was undertaken to contribute in the domain with perspectives from a developing country like Niger endowed with huge potential of solar energy resources. All experiments were conducted under climatic conditions of Niamey (Niger).

$$
\begin{array}{r}
P_{v s a t}=\exp \left(23.3265-\frac{1}{T_{a}+2}\right. \\
P_{v s a t}=\exp \left(23.1964-\frac{3816.44}{T_{a}+227.05}\right) \text { for } T_{a}>45^{\circ} \mathrm{C}
\end{array}
$$

\subsection{Drying Curves}

The general form of a curve characterizing the drying kinetics of solids is obtained by plotting the product moisture content dry basis $(M p)$ against time $(\mathrm{t})$. The most completed form of a drying curve consists of a transition phase where the product is eventually being heated, a constant-rate drying phase corresponding to the evaporation of free water on the surface of the product [8] and a Falling-rate drying phase characterized by a decrease in the migration of humidity from inside the product when this humidity is no longer sufficient to saturate the surface of the product [9].

For fruits, most vegetables and most tropical tuber crops, the initial moisture content is above the critical moisture content usually, thus the drying of these products would take place within both the constant and falling-rate drying periods [10].

\subsection{Determination of Drying Constants}

Drying constants are determined from graphical representation of moisture content Mp $\left(\mathrm{kg}\right.$ water $\left.^{\mathrm{kg} \text { dry matter }}\right)$ of tomato, potato, okra and mango; the drying rate $D R\left({ }^{\mathrm{kg} \text { water }} / \mathrm{kg}\right.$ dry matter $/$ min $)$ and the moisture ratio $M R$ (eq. 4) over time.

$$
M R=\frac{M_{t}-M_{e}}{M_{0}-M_{e}}
$$

\section{Theoretical Background}

\subsection{Drying Air Humidity}

The drying kinetics of tomato, mango, potato and okra was established by analysing the evolution of $\Delta X$ over time. $\Delta X=X_{\text {out }}-X_{\text {in }}$ represents the difference between absolute humidity of the drying air at the exit and the entrance of the tunnel dryer. The absolute humidity $X$ of the inlet and outlet drying air was calculated based on equation (1):

$$
X=0.622 * \frac{\varphi * P_{v s a t}}{P-\varphi * P_{v s a t}}
$$

$\varphi$ represents the relative humidity (\%).

$P_{\text {vsat }}$ the saturation vapour pressure of water at the operating temperature $(\mathrm{Ta})$.

$P$ total pressure equals to the atmospheric pressure $(\mathrm{Pa})$.

Nadeau J. P. et al. [7] proposed equations (2) and (3) for the calculation of $P_{v s a t}$.

$M_{t}$ is the moisture content of the product at any time $(\mathrm{kg}$ water $/ \mathrm{kg}$ dry matter),

$M_{e}$ moisture content at equilibrium ( $\mathrm{kg}$ water $/ \mathrm{kg}$ dry matter),

$M_{0}$ initial moisture content ( $\mathrm{kg}$ water $/ \mathrm{kg}$ dry matter).

Luikov equations derived from the second law of Fick on diffusion, govern the variation of moisture ratio over time $[11,5]$. Water diffusivity in tomato, potato, mango slices and okra pellets can be calculated from Luikov equations 5 and 6 used to predict the gradient of temperature (T) and moisture (M) inside the product to be dried.

$$
\begin{gathered}
\frac{\partial M}{\partial t}=D_{\text {eff }}\left[\frac{\partial^{2} M}{\partial x^{2}}+\frac{a_{1}}{x} \frac{\partial M}{\partial x}\right] \\
\frac{\partial T}{\partial t}=\alpha\left[\frac{\partial^{2} T}{\partial x^{2}}+\frac{a_{1}}{x} \frac{\partial T}{\partial x}\right]
\end{gathered}
$$

Parameter $\mathrm{a} 1=0$ for planar geometries, $\mathrm{a} 1=1$ for cylindrical shapes and $\mathrm{a} 1=2$ for spherical shapes $[10,12]$.

Analytical solutions of equation 5 leads to equation 7 valid over the falling-rate phase [13]:

$$
M R=\frac{M_{t}-M_{e}}{M_{c r}-M_{e}}=A_{1} \sum_{i=1}^{\infty} \frac{1}{(2 i-1)^{2}} \exp \left(-\frac{(2 i-1)^{2} \pi^{2} D_{e f f} t}{A_{2}}\right)
$$

$M_{c r}$ is the moisture content of the tomato slices at critical point. $A_{1}$ and $A_{2}$ are constants (table 1) depending on the geometry of the product being dried.

Table 1. Values of geometric constants $A_{1}$ and $A_{2}$ according to the product geometry.

\begin{tabular}{lll}
\hline Product geometry & $\boldsymbol{A}_{\mathbf{1}}$ & $\boldsymbol{A}_{\mathbf{2}}$ \\
\hline Infinite slab (H is half thickness of slab) & $\frac{8}{\pi^{2}}$ & $4 H^{2}$ \\
Sphere with $\mathrm{r}$ as radius & $\frac{6}{\pi^{2}}$ & $4 r^{2}$ \\
\hline
\end{tabular}


Henderson and Pabis [14] proposed a model for describing drying process by using Fick's second law of diffusion. For sufficiently long drying times, only the first term $(i=1)$ of the general series solution of equation 7 can be used with small error [12]. Equation 7 can therefore be written as:

$$
M R=\frac{M_{t}-M_{e}}{M_{c r}-M_{e}}=A_{1} \exp \left(-\frac{\pi^{2} D_{e f f}}{A_{2}} t\right)
$$

Assuming $D_{\text {eff }}$ is constant during the drying process, equation 8 can be written as:

$$
M R=\frac{M_{t}-M_{e}}{M_{c r}-M_{e}}=a \cdot \exp (-k \cdot t)
$$

where $a$ and $k$ are drying constants in the Henderson and Pabis Model. Ibrahim Doymaz et al. [11] and Reyes A. et al. [15] successfully used this model in describing the drying kinetics of tomato slices.

The Page Model was developed by Page, C. [16]. This model was widely used to describe drying kinetics of food materials.

The Page Model is a simple exponential model, which approximated the $\frac{8}{\pi^{2}}$ ratio as being equal to unity but introduced new constants as follows:

$$
M R=\exp \left(-k t^{y}\right)
$$

where $\mathrm{k}$ and $\mathrm{y}$ are drying constants associated with this model.

Several authors including Kamil Sacilik et al. [5] and Hadi Samimi-Akhijani et al. [17] used this model to describe drying properties of tomato slices.

\subsection{Effective Water Diffusivity}

Calculation of effective water diffusivity was based on equation 7. Assuming slab geometry for tomato, potato and mango slices, equation 7 can further be simplified in a linear form as follows:

$$
\ln (M R) \approx \ln \left(\frac{M_{t}}{M_{c r}}\right)=\ln \left(\frac{8}{\pi^{2}}\right)-\left(\frac{\pi^{2} D_{e f f}}{4 H^{2}} t\right)
$$

Where, $D_{\text {eff }}$ is given by the slope $\alpha=\frac{\pi^{2} D_{e f f}}{4 H^{2}}$

$H$ is the half thickness of the slices if drying occurs from both sides, or $H$ is the thickness of the slices if drying occurs from only one side [12]. In our experiments, drying was taking place through both sides of the slices.

Plotting $\ln (M R)=f(t)$ allow the determination of the slope of eq. 11 and subsequently the determination of $D_{e f f}$.

Similarly, assuming a spherical geometry for okra pellets, equation 7 could be simplified as follows:

$$
\begin{gathered}
\ln (M R) \approx \ln \left(\frac{M_{t}}{M_{c r}}\right)=\ln \left(\frac{6}{\pi^{2}}\right)-\left(\frac{\pi^{2} D_{e f f}}{4 r^{2}} t\right) \\
D_{e f f} \text { is given by the slope } \alpha=\frac{\pi^{2} D_{e f f}}{4 r^{2}}
\end{gathered}
$$

Application of Fick's second law of diffusion in the calculation of water diffusivity required assumptions of moisture migration being governed by diffusion, negligible or constant shrinkage of products, constant diffusion coefficients and temperature $[18,19]$.

\section{Materials and Methods}

\subsection{Materials}

\subsubsection{Thermo Hygrometers}

The thermo hygrometers served to measure relative humidity and temperature of the inlet and outlet drying air. The specifications of these thermo hygrometers are summarized in table 2 .

Table 2. Specifications of thermo hygrometers.

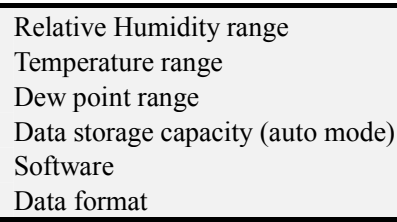

The thermo hygrometers act as data loggers with automatic and manual logging modes. In the automatic logging mode, the thermo hygrometers' memory can store up to 8124 records at time intervals of 10 seconds to 24 hours.

\subsubsection{Anemometer}

A Kestrel type thermo anemometer $(0.3$ to $40 \mathrm{~m} / \mathrm{s}$ sensibility) served to measure the speed of the drying air. Air temperature and relative humidity ranges are -29 to $70^{\circ} \mathrm{C} \pm$ $1^{\circ} \mathrm{C}$ and 5 to $95 \% \pm 3 \%$ respectively.

\subsubsection{The Precision Balance}

A SCALIX CB-310 model balance was used to weight the products before and after the drying process. The capacity

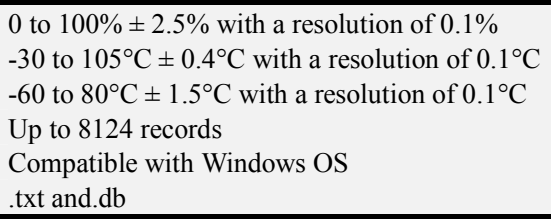

and the precision of the balance are $300 \mathrm{~g}$ and $0,01 \mathrm{~g}$ respectively.

\subsubsection{The Cutting Tools}

Cutting tools were used to for peeling and trenching the products into regular tranches in preparations for drying. These cutting tools include a kitchen slicer and few knives.

\subsubsection{Moisture Analyser}

A PCE-MA Series moisture analyser was used to determine the initial $\left(M_{0}\right)$ and final moisture contents $\left(M_{f}\right)$ of product samples. Three heat-up modes are available. The Standard heat-up mode is the default mode which is suitable for most sample types. In this heat-up mode, $120^{\circ} \mathrm{C}$ are 
reached after approximately 4 minutes. The Quick heat-up mode is suitable for samples with a high moisture content. In this heat-up mode, $120^{\circ} \mathrm{C}$ are reached after approximately 1 minute. The Slow heat-up mode is suitable for samples with low moisture content. In this heat-up mode, $120^{\circ} \mathrm{C}$ are reached after approximately 8 minutes.

Dry matter, initial and final moisture content of product samples were determined by using the Standard heat-up mode. The measurement is stopped automatically when the measured value is constant over a certain period of time.

\subsubsection{Experimental Dryer}

Our locally manufactured experimental dryer is a forcedconvective tunnel dryer made up of a one-millimetre thick metallic sheet. The experimental appliance in figure 1 gives the form and the size of the dryer.

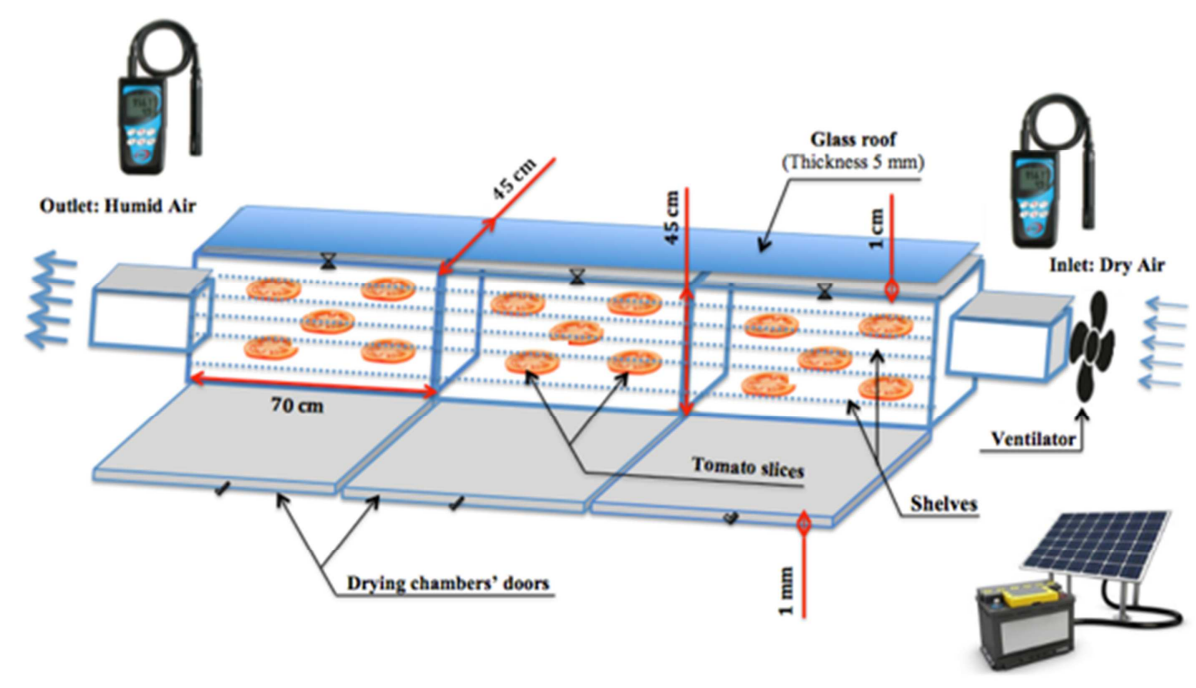

Figure 1. Diagram of the experimental appliance.

\subsection{Method}

\subsubsection{Preparation of the Products}

For tomato, ripen fruits were selected bearing in mind to avoid fruits that are either too ripe (broken) or hard (not ripe enough). The product is then weighted, washed, wiped and cut into circular slices of approximately $3 \mathrm{~mm}$ thick. The tomatoes are then placed on shelves in the drying chambers. The variety of tomato we used is called " Roma ". It is locally produced, primarily during cold season [20].

For Okra, the product was washed, wiped, weighted and cut into circular pellets of approximately 5 millimetre-thick. The variety we used is called "Clemson Spineless". It is locally cultivated essentially in dry season [20]. This variety is very gluey and has pods that are 2 to 3 centimetres thick. The pods contain small grains that do not fall down even if the pods are cut into pellets.

For mango, the ripe fruits were washed, wiped and weighted. The pulp was separated from the skin and the stone, and sliced into pieces of around $5 \mathrm{~mm}$ thick and 7 to $10 \mathrm{~cm}$ long. Kent mango variety largely grown in West Africa $[13,21]$ was used for the experiments.

Freshly potato cultivar was manually peeled, washed and sliced into slices of around $3 \mathrm{~mm}$ thick using kitchen slicer. The variety used for the experiment was the «Sahel» variety which is also one of the most commonly grown in Niger [22].

For each of the products to be dried (fresh tomato, potato, mango and okra), around seven kilograms of product were used in each drying experiment.

The drying rate reduces by $4.5 \%$ as a result of a $1 \mathrm{~mm}$ thickness increase [23] so the need for thin slices with a thickness ranging from 3 to 5 millimetres.

\subsubsection{Experimental Procedure}

The drying experiments were launched in the morning at 10:00 am $\pm 20 \mathrm{~min}$ local time. The dryer was placed under sun heat. The entire drying energy is therefore coming from the sun. In order to capture a maximum solar heat, the tunnel dryer was placed in a West-East direction. The products to be dried were evenly placed on shelves in the drying chambers. A fan powered by a solar panel was used for air convection throughout the tunnel dryer (figure 1). After every minute, the two thermo hygrometers automatically record the values of the drying air relative humidity, temperature and dew point at the entry and exit of the experimental dryer. In order to eliminate the maximum of water content from the product and predict its storage conditions, the drying process was conducted continuously and over two consecutive days without interruption. This experimental procedure was repeated for each of the products to be dried (tomato, mango, okra and potato slices) at a constant drying air velocity of $2.5 \mathrm{~m} / \mathrm{s}$.

\subsubsection{Data Collection}

"Direct" experimental methods of data collection for characterizing drying kinetics generally consist in monitoring weigh losses on the product during a thin-layer $(0$ to $3 \mathrm{~cm}$ ) drying process $[24,25,17,23]$. The rate of humidity of the product is being measured at regular time intervals or eventually continuously by the means of an electronic balance that records the mass of the product over time [26].

In our work, the method we used for characterizing drying kinetics for tomato, potato, mango and okra, was rather based 
upon the "indirect" method which consisted in recording over time, the inlet and outlet variation of the humidity of the drying air instead of the humidity of the product itself [27].

The "direct" and the "indirect" approaches are the same in the sense that weight losses of the product are equivalent to humidity gains of the drying air.

\subsubsection{Data Analysis}

After the two days of experimentation, the recorded data (temperature, relative humidity and dew point of the drying air) were transferred from the data loggers to a computer in the form of tables. The values of recorded drying air relative humidity $\varphi$ were converted into absolute humidity $X$. From a mass balance, the amount of water $\left(\Delta X=X_{\text {out }}-X_{\text {in }}\right)$ transported by the inlet and outlet drying air was calculated. Assuming that, the moisture gains $(\Delta X)$ of the drying air was taken from the products, dry basis moisture content and drying rate were calculated. A mass balance was applied to convert $\Delta X$ into product weight losses and subsequently calculate its moisture content on a dry basis $M_{t}$ at any time. Derivation of $M_{t}=f(t)$ led to the calculation of the drying rate $D R$. Product moisture ratio at any time was therefore calculated based on equation 4 .

\subsubsection{Simulation Models}

Moisture ratio versus moisture content dry basis curves were adjusted in one hand with the Henderson\& Pabis Model, given by Eq. 9 and in another with the Page Model given by equation 10 to determine the values of drying constants $k, a$ and $y$. The adjustment was performed by the use of Solver Tool from Microsoft Excel 2011 software, minimizing the root mean square error between the experimental values and those calculated based on the models.

\section{Results and Discussion}

\subsection{Experimental Conditions}

All drying experiments were conducted under uncontrolled temperature and air humidity conditions. Drying air temperature and humidity are governed by ambient weather conditions at the moments of the experiments. Drying air velocity was however maintained at a constant value of 2.5 $\mathrm{m} / \mathrm{s}$ for all experiments. Figures 2 and 3 show the evolution over time of drying air temperature and relative humidity during experiments with okra, tomato, mango and potato.

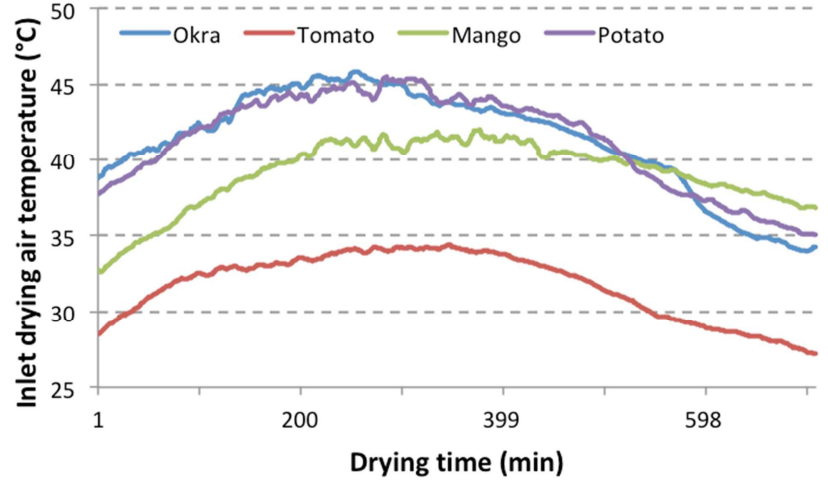

Figure 2. Evolution over time of inlet drying air temperature during experiments with okra, tomato, mango and potato.

The experiments took place in Niamey between $24^{\text {th }}$ of April 2018 and the $3^{\text {rd }}$ of May 2019. For each of these experiments, drying air temperature depends on ambient conditions. Experiments with potato and okra took place within a one-week timeframe. This explains the slight differences in drying air temperatures and relative humidity (figure 2 and figure 3 ).

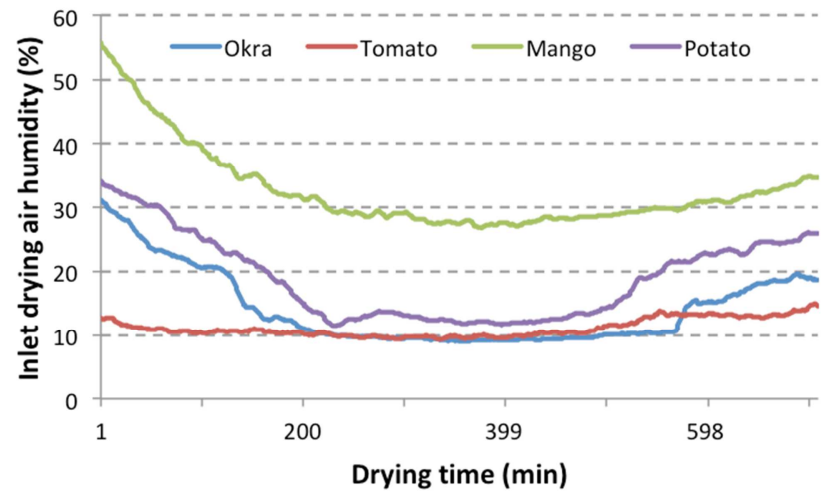

Figure 3. Evolution over time of inlet drying air relative humidity during experiments with okra, tomato, mango and potato.

Experiments with mango and tomato took place within the raining season (June) and the dry season (March) respectively (table 3 ). As per experiments with potato and okra, they took place in-between the raining and the dry season. This explains the progressive shift of the drying air humidity, which increased in the following order: (1) experiment with tomato, (2) experiment with okra and potato and (3) experiment with mango (table 3 ).

Table 3. Experimental conditions.

\begin{tabular}{llll}
\hline & Okra & Tomato & Mango \\
\hline First day of experiment & 1 May 2018 & 3 March 2019 & 7 June 2018 \\
Starting time of experiment & $10: 45$ am & $10: 50$ am & $09: 12$ am \\
Average temperature of inlet drying air $\left({ }^{\circ} \mathrm{C}\right)$ & 41.35 & 31.76 & $39 \cdot 10$ \\
Average relative humidity of inlet drying air $(\%)$ & 14.07 & 11.12 & 32.66 \\
\hline
\end{tabular}

The four experiments were launched in the morning between 9:12 am and 10:50 when the ambient air temperature was increasing while its relative humidity was declining. Drying air humidity was quite stable during experiment with tomato. This could be explained by the fact that March was an entirely dry and cold month in Niamey. According to our records, ambient air relative humidity and temperature were relatively stable between 1:00 pm and 4:00 
pm during all experiments (figures 2 and 3 ).

\subsection{Drying Curves}

Under the abovementioned experimental conditions, we analysed drying kinetics of mango, tomato, okra and potato based on the absolute humidity of the drying air, the Krisher representation of drying curve, the evolution over time of the moisture ratio and its linearized form (figure 4 to figure 18).

\subsubsection{Drying Curves for Mango}

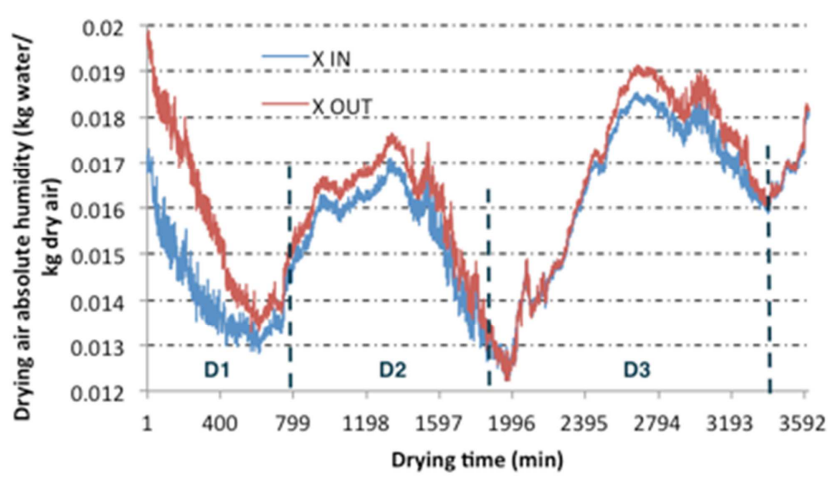

Figure 4. Absolute humidity of inlet (X IN) and outlet (X OUT) drying air for mango.

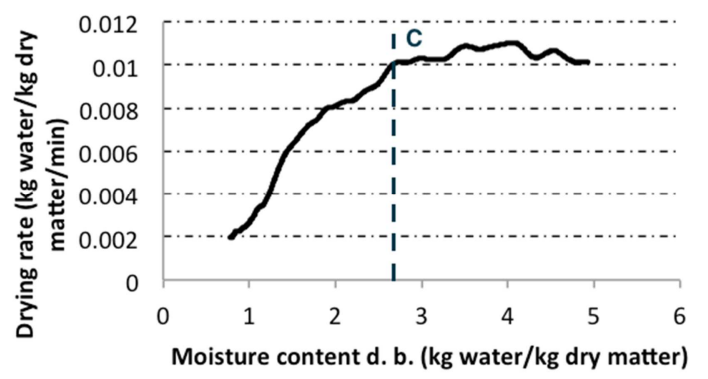

Figure 5. Krisher form of drying curve for mango.

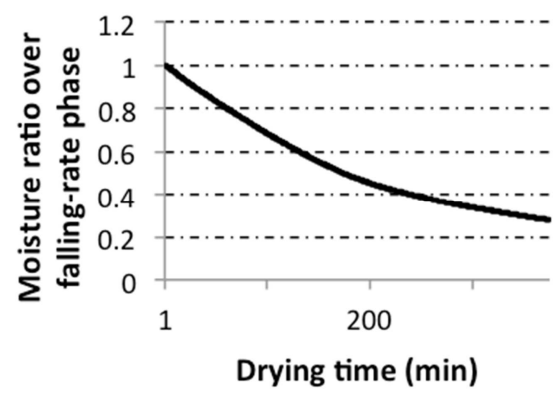

Figure 6. Evolution of moisture ration over time for mango.

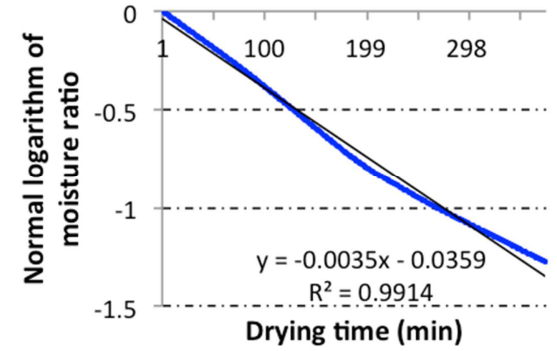

Figure 7. Linearization of moisture ration for mango.

\subsubsection{Drying Curves for Tomato}

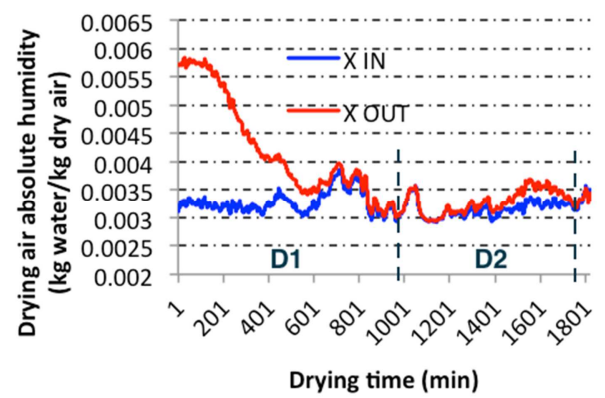

Figure 8. Absolute humidity of inlet (X IN) and outlet (X OUT) drying air for tomato.

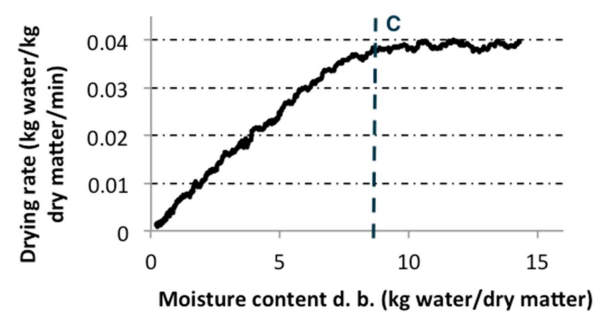

Figure 9. Krisher form of drying curve for tomato.

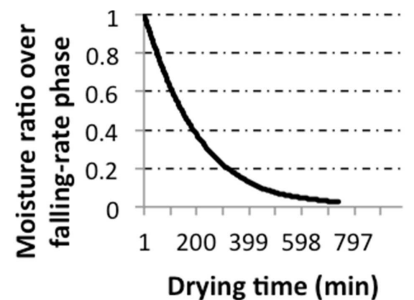

Figure 10. Evolution of moisture ration over time for tomato.

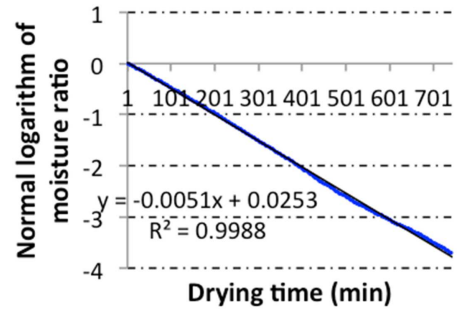

Figure 11. Linearization of moisture ration for tomato.

\subsubsection{Drying Curves for Okra}

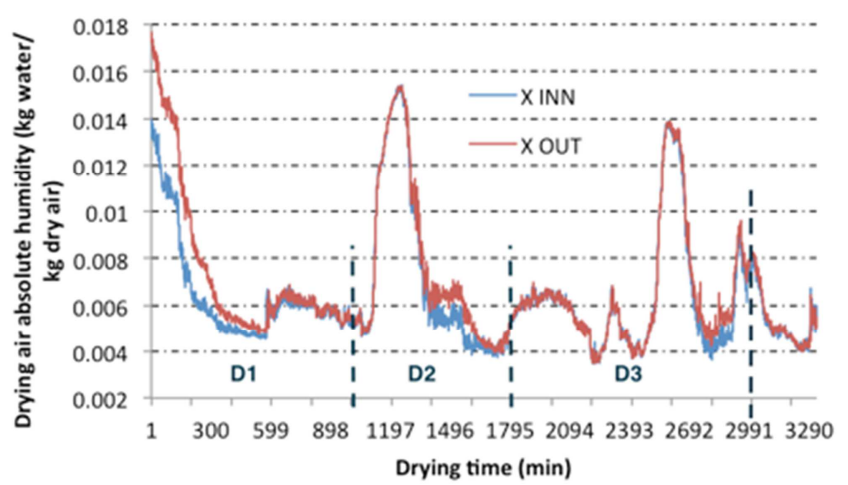

Figure 12. Absolute humidity of inlet (XIN) and outlet (X OUT) drying air for okra. 


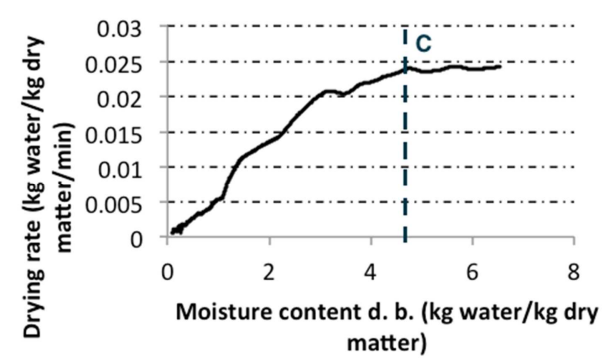

Figure 13. Krisher form of drying curve for okra.

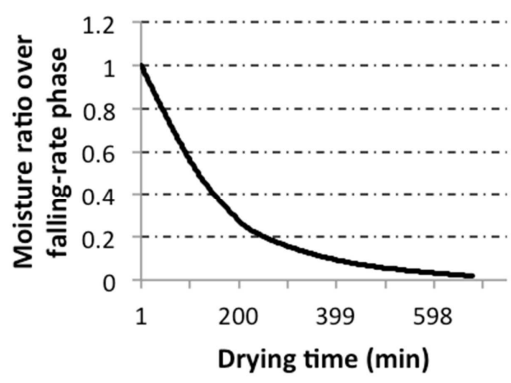

Figure 14. Evolution of moisture ration over time for okra.

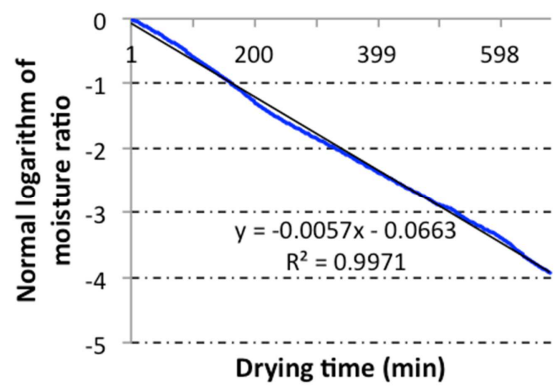

Figure 15. Linearization of moisture ration for okra.

\subsubsection{Drying Curves for Potato}

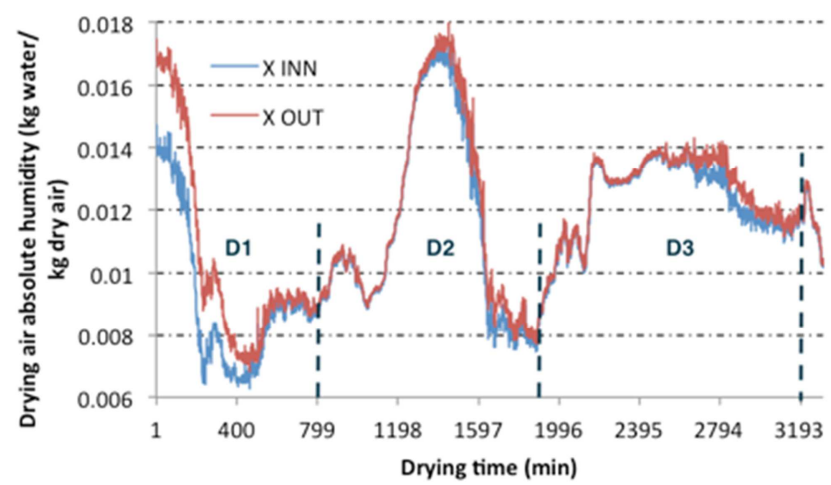

Figure 16. Absolute humidity of inlet (X IN) and outlet (X OUT) drying air for potato.

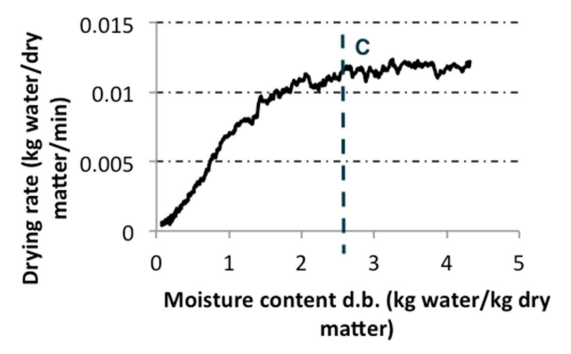

Figure 17. Krisher form of drying curve for potato.

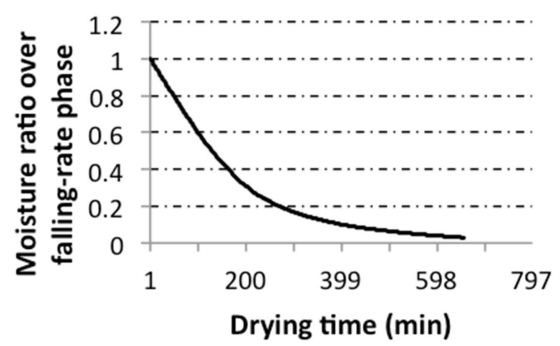

Figure 18. Evolution of moisture ration over time for potato.

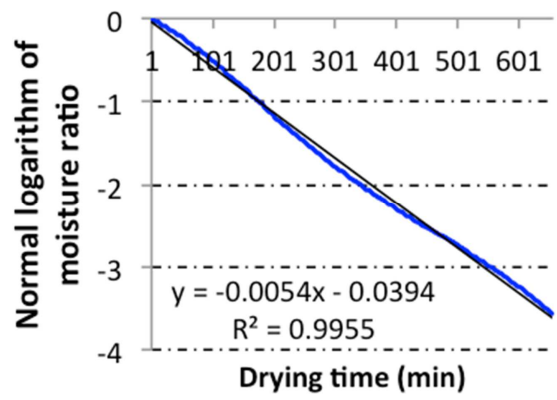

Figure 19. Linearization of moisture ration for potato.

\subsection{Interpretations of Drying Curves}

Figures 4, 8, 12 and 16 inform about the drying time. Drying experiments took place over 2 days (figure 8) to 3 days (figure 4, 12 and 16) and drying process resumed according to daily solar cycle. D1, D2 and D3 indicate the days of drying. The red curves represent the absolute humidity of the drying air at the exit $\left(X_{\text {out }}\right)$ of the dryer. The blue curves represent the absolute humidity of the drying air at the entrance $\left(X_{\text {in }}\right)$ of the dryer. Whenever $X_{\text {out }}$ is above $X_{\text {in }}$, this indicates daytimes and that drying process is taking place. When red curve and the blue curve overlap, it means no drying is taking place. This happens over nights when the sun energy is no longer available. The bigger the difference between $X_{\text {out }}$ and $X_{\text {in }}$, the higher the drying rate. The quicker the first overlap between the red curve and the blue curve, the shorter the drying time.

Table 4. Graphical values of moisture contents at critical points for mango, tomato, okra and potato.

\begin{tabular}{llll}
\hline & $\begin{array}{l}\text { Critical moisture content (d.b.) (kg } \\
\text { water/kg dry matter) }\end{array}$ & Critical time (min) & $\begin{array}{l}\text { Critical drying rate (kg water/kg dry } \\
\text { matter/min) }\end{array}$ \\
\hline Mango & 2.784 & 205 & 0.010 \\
Tomato & 8.999 & 139 & 0.038 \\
Okra & 4.895 & 70 & 0.023 \\
Potato & 2.644 & 144 & 0.011 \\
\hline
\end{tabular}


Figures 5, 9, 13 and 17 show the Krysher form of drying curves. These curves clearly show the existence of both a constant-rate and a falling rate drying phases. The end of the constant drying rate period (point $\mathrm{C}$ ) is characterized by a decrease in the migration of humidity from inside the product so that this humidity is no longer sufficient to saturate the surface of the product [9]. At this stage referred to as the critical point (Table 4), environmental conditions (vapour pressure between the drying air and the surface of the product, the surface of the product which is exposed to the drying air, the drying air velocity), no longer play a significant role on the drying rate [10]. This phase is rather governed by water diffusivity towards the surface of the product but also by the speed at which water is evacuated when it reaches the surface of the product [28]. The product is therefore said to have entered in a hygroscopic phase [29].

Several authors reported the non-existence of the constantrate drying phase but in different experimental conditions. Ibrahim Doymaz et al. [25] who carried out a laboratoryscale hot-air drying experiments of okra in which air velocity was kept at a constant value of $1.0 \mathrm{~m} / \mathrm{s}$ while drying air temperatures were set to 50,60 and $70^{\circ} \mathrm{C}$ and relative humidity of $25 \%, 15 \%$ and $8 \%$ respectively. Weight loss of $100 \mathrm{~g}$ of okra samples was measured by means of a load cell and was recorded at 30 min intervals.

Hadi Samimi-Akhijahani et al. [17] used a lab-scale photovoltaic-ventilated solar dryer equipped with a collector in drying experiments of tomato. Drying air velocities applied were $0.5,1$, and $2 \mathrm{~m} / \mathrm{s}$. The tomato samples were weighed at $30 \mathrm{~min}$ intervals using an electronic digital weighing balance.

P. K. Wankhade et al. [30] performed a hot air drying of a $100 \mathrm{~g}$ sample of okra pellets at 40,60 and $90^{\circ} \mathrm{C}$ air temperatures and a constant air velocity of $1 \mathrm{~m} / \mathrm{s}$. Moisture losses of samples were recorded with the help of a digital electronic balance at $10 \mathrm{~min}$ intervals for first one hour and 20 min subsequently thereafter for determination of drying curves.

L. Villa-Corrales et al. [23] conducted mango-drying experiments under controlled conditions of air drying temperatures of $50,55,60,65$ and $70^{\circ} \mathrm{C}$. The relative humidity and air velocity were fixed. The weigh of the sample was measured along the test by using a load cell. The air-drying velocity was $0.2 \mathrm{~m} / \mathrm{s}$ and drying was set to take place only on the upper face of the mango slices.

The above authors concluded that drying was taking place only in a falling-rate phase.

On the other hand, the authors below reported the existence of both a constant-rate and a falling-rate drying phases.

S. Toure et al. [31] conducted natural solar drying of cassava, ripe or raw plantain banana and mango and observed a constant-rate drying period, a falling-rate period and the transition between these two periods.

Mohamed A. Eltawil et al. [32] analysed moisture content of blanched potato slices during a convective drying process with three different airflow rates $(2.1,3.12$ and 4.18 $\mathrm{m}^{3} / \mathrm{min}$ ). Moisture content of samples was determined at 60 min and 30 min time intervals by the difference in mass resulting from the weighing of the samples. They observed that drying process of potato slices takes place in two different stages namely the constant-rate and the falling-rate drying stages.

\section{Modelling of Drying Process}

Figures 6, 10, 14 and 18 show the evolution over time of experimental moisture ratios for mango, tomato, okra and potato slices. We applied two drying models to describe moisture ration variations over time in each of the experiments. These models are the Henderson \& Pabis Model (Eq. 9) and the Page Model (Eq. 10). Both models were derived from Fick second law of diffusion. Drying constants associated with the Henderson \& Pabis Model are summarized in Table 5.

Assessment of the models was based on associated correlation factor $\chi^{2}$ compared with experimental data. The smaller $\chi^{2}$, the better the model. Table 5 summarizes the correlation factors (model constants) for potato, mango, okra and tomato associated with the Henderson \& Pabis Model and the Page Model.

Table 5. Model constants and $\chi^{2}$ correlation factors.

\begin{tabular}{lrrrr}
\hline Model constants & Mango & Tomato & Okra & Potato \\
\hline \multicolumn{2}{l}{ Henderson\& Pabis Model } & & & \\
$\mathrm{a}$ & 0.9931 & 1.0298 & 1.0786 & 1.0494 \\
$\mathrm{k}$ & 0.0036 & 0.0050 & 0.0057 & 0.0058 \\
$\chi^{2}$ & 0.0825 & 0.0221 & 0.2051 & 0.0909 \\
Page Model & & & & \\
$\mathrm{k}$ & 0.0048 & 0.0035 & 0.0021 & 0.0035 \\
$\mathrm{y}$ & 0.9500 & 1.0598 & 1.1686 & 1.0824 \\
$\chi^{2}$ & 0.0638 & 0.0051 & 0.0922 & 0.0978 \\
\hline
\end{tabular}

Based on the analysis of $\chi^{2}$ factors, it appears that the Page Model better describe the evolution of moisture ratio over time for all four experiments.

\section{Water Diffusivity}

Diffusivity is a key parameter for designing and calculating of industrial dryers [33]. It is a function of the product to be dried but it is mainly a function of operating conditions [19]. The effective moisture diffusivity increases with increasing air velocity [17] and temperature [25].

Figures 7, 11, 15 and 19 are derived from experimental values of moisture ratio and equation 11 , which represents a linear form of the Fick second law of diffusion. Critical moisture contents are determined graphically (Table 4). The linearized forms of experimental values of moisture ratios were therefore fitted with a first order polynome $(y=\alpha *$ $x+\beta)$ in which $\alpha$ represents the slope of the line (Eq. 11 and Eq. 12). Corresponding $\mathrm{R}^{2}$ are summarized in table 6. From our experiments, we found values of $D_{\text {eff }}$ raging from $4.559 \times 10^{-09}$ to $8.866 \times 10^{-09}$ for tomato, potato, okra and mango (table 6). 
Table 6. Effective moisture diffusivity.

\begin{tabular}{lllll}
\hline & Mango & Tomato & Okra & Potato \\
\hline$D_{\text {eff }}\left(\mathrm{m}^{2} / \mathrm{s}\right)$ & $8.866 \mathrm{E}-09$ & $4.651 \mathrm{E}-09$ & $5.177 \mathrm{E}-09$ & $4.969 \mathrm{E}-09$ \\
$\mathrm{R}^{2}$ & 0.9914 & 0.9988 & 0.9970 & 0.9955 \\
\hline
\end{tabular}

Madamba et al. [34] found that for food materials, $D_{\text {eff }}$ values are in the range of $10^{-11}$ to $10^{-9} \mathrm{~m}^{2} / \mathrm{s}$. Moreover, Zafer Erbay et. al. [12] found statistical accumulation (86,2\%) of $D_{\text {eff }}$ values of foods that were dried in a convective type batch dryer, in the region of $10^{-10}$ to $10^{-8} \mathrm{~m}^{2} / \mathrm{s}$. These values are both in line with those we found for tomato, potato, okra and mango.

Maximum values of the moisture diffusivity for tomato slices were found to range from $1.31 \times 10^{-9} \mathrm{~m}^{2} / \mathrm{s}$ to $1.59 \times 10^{-9}$ $\mathrm{m}^{2} / \mathrm{s}$ for air velocity of $0.5 \mathrm{~m} / \mathrm{s}$. These values shifted to a range of $4.24 \times 10^{-9}$ to $6.98 \times 10^{-9}$ when air velocity reaches 2 $\mathrm{m} / \mathrm{s}$ while the thickness of the tomato slices was fixed to 7 $\mathrm{mm}[17]$.

Ibrahim Doymaz et al. [25] found water diffusivity in okra as being equal to $4.27 \times 10^{-10} ; 7.76 \times 10^{-10}$ and $1.30 \times 10^{-9} \mathrm{~m}^{2} / \mathrm{s}$ at 50,60 and $70^{\circ} \mathrm{C}$, respectively.

L. Villa-Corrales et al. [23] reported values of diffusivity varying from $4.41 \times 10^{-10}$ to $5.95 \times 10^{-10} \mathrm{~m}^{2} / \mathrm{s}$ during a convective drying of mango for inlet air temperatures ranging from 50 to $70^{\circ} \mathrm{C}$.

Kamil Sacilik et al. [5] established a mathematical modelling of solar tunnel drying of thin layer organic tomato at an ambient temperature raging from 22.4 to $35.6^{\circ} \mathrm{C}$. They found the value of effective diffusivity for solar tunnel drying process to be $1.31 \times 10^{-9} \mathrm{~m}^{2} / \mathrm{s}$. Giovanelli G. et al. [35] reported that the diffusivity values changed from $2.26 \times 10^{-9}$ to $9.14 \times 10^{-9} \mathrm{~m}^{2} / \mathrm{s}$ as a function of the structure of tomato products for hot air drying.

Wei Wang et al. [36] used an indirect forced convection solar dryer with auxiliary heating device to dry mango slices weighed periodically at $1 \mathrm{~h}$ intervals using a digital balance. They used Fick's diffusion model and found Deff of mango slices varying from $6.41 \times 10^{-11}$ to $1.18 \times 10^{-10} \mathrm{~m}^{2} / \mathrm{s}$ over the temperature range of $40-52^{\circ} \mathrm{C}$.

An increase in air velocity corresponds to a decrease in external resistances to heat and mass transfer. This results in faster drying [37].

\section{Conclusion}

Our results revealed the existence of both a constant and a falling-rate drying phases. The existence of a constant and a falling rate phases is strongly related to the experimental conditions, in our case, the continuous but indirect measurements of water losses in the product being dried during the experiments. This is in contrast with intermittent disruption of experiments in order to measure weight loss on the product, which is likely to disturb the system and prevent from observing a constant rate phase. Conducting our experiments in real-world conditions with uncontrolled temperature and drying air humidity was another significant difference compared with drying experiments conducted in laboratories. As per the values of effective diffusivity $\left(D_{\text {eff }}\right)$ of water, our results $\left(4.559 \times 10^{-09} \mathrm{~m}^{2} / \mathrm{s}\right.$ to $\left.8.866 \times 10^{-09} \mathrm{~m}^{2} / \mathrm{s}\right)$ are in the range of values $\left(10^{-10}\right.$ to $\left.10^{-8} \mathrm{~m}^{2} / \mathrm{s}\right)$ agreed by majority of authors we reviewed. Simulation of moisture ratios with the Henderson \& Pabis Model and the Page Model reveled that the Page Model better describe the drying processes for mango, tomato, okra and potato slices.

\section{Acknowledgements}

We would like to thank Professor Eric DOMONT (Service de Thermodynamique - Ecole Polytechnique de Mons Université de Mons, Belgique), Professeur Emérite Jacques BOUGARD (Ingénieur Civil AIMs - Ecole Polytechnique de Mons - Université de Mons, Université Libre de Bruxelles Belgique) for providing valuable help in data analysis.

\section{Nomenclature}

\begin{tabular}{|c|c|}
\hline$X$ & Absolute humidity of the inlet and outlet drying air ( $\mathrm{Kg}$ water/Kg dry air) \\
\hline$\varphi$ & Drying air relative humidity $(\%)$. \\
\hline$P_{v s a t}$ & Saturation vapour pressure of water (Pascal). \\
\hline$T_{a}$ & Operating temperature $\left({ }^{\circ} \mathrm{K}\right)$ \\
\hline$P$ & Total pressure equals to the atmospheric pressure (Pascal). \\
\hline$M R$ & Moisture ration of the product \\
\hline$M_{p}$ & Moisture content of the product ( $\mathrm{kg}$ water $/ \mathrm{kg}$ dry matter), \\
\hline$M_{t}$ & Moisture content of the product at any time ( $\mathrm{kg}$ water $/ \mathrm{kg}$ dry matter), \\
\hline$M_{e}$ & Moisture content of the product at equilibrium ( $\mathrm{kg}$ water $/ \mathrm{kg}$ dry matter), \\
\hline$M_{0}$ & Initial moisture content of the product ( $\mathrm{kg}$ water $/ \mathrm{kg}$ dry matter). \\
\hline$M_{c r}$ & Critical moisture content of the product ( $\mathrm{kg}$ water $/ \mathrm{kg}$ dry matter). \\
\hline $\mathrm{k}, \mathrm{a}, \mathrm{y}$ & Drying constants in the Henderson \& Pabis Model and the Page Model \\
\hline$D_{e f f}$ & Effective water diffusivity in Okra, Tomato, Mango and Potato $\left(\mathrm{m}^{2} / \mathrm{s}\right)$ \\
\hline $\mathrm{H}$ & Thickness - assuming slab geometry for mango, tomato and potato slices (m) \\
\hline $\mathrm{r}$ & Radius - assuming spherical geometry for okra pellets (m) \\
\hline
\end{tabular}




\section{References}

[1] Serhat Turgut, S., Küçüköner, E., Karacabey, E., (2017). Improvements in drying characteristics and quality parameters of tomato by carbonic maceration pretreatment. J. Food Process. Preserv. (in press). doi: http://dx.doi.org/10.1111/jfpp.13282.

[2] Mahdiyeh Dorouzi et al., (2018). Tomato slices drying in a liquid desiccant-assisted solar dryer coupled with a photovoltaic-thermal regeneration system - Department of Mechanical Engineering of Biosystems, Faculty of Agriculture, Shahid Bahonar University of Kerman.

[3] Lahsasni, S., Kouhila, M., Mahrouz, M., Idlimam, A., \& Jamali, A. (2004). Thin layer convective solar drying and mathematical modelling of prickly pear peel (Opuntia ficus indica). Energy, 29 (2), 211-224.

[4] Tiris, C., Tiris, M., \& Dinc er, I. (1996). Energy efficiency of a solar drying system. International Journal of Energy Research, 20 (9), 767-770.

[5] Kamil Sacilik, Rahmi Keskin, Ahmet Konuralp Elicin, (2005). Mathematical modelling of solar tunnel drying of thin layer organic tomato - Department of Agricultural Machinery, Faculty of Agriculture, Ankara University, 06130 Ankara, Turkey.

[6] Steinfeld, A., \& Segal, I. (1986). A simulation model for solar thin-layer drying process. Drying Technology, 4, 536-554.

[7] Nadeau (J. P.) et PUIGGALI (J. R.). (1995). Séchage: des processus physiques aux processus industriels, Lavoisier Tec \& Doc, $307 \mathrm{p}$.

[8] Catherine Bonazzi et Jean-Jacques Bimbenet, (2003). Séchage des produits alimentaires: Principes - Institut national agronomique de Paris-Grignon (INA - P-G) - École nationale supérieure des industries agricoles et alimentaires (ENSIA).

[9] André Charreau et Roland Cavaillé, (1995). Séchage, Théorie et calculs - Techniques de l'Ingénieur, traité Génie des procédés.

[10] O. Val Ekechukwu, (1995). Drying Preinciples and Theory: An Overview » University of Nigeria and the International Centre for Theoretical Physics, Trieste, Italy. 25 p.

[11] Ibrahim Doymaz (2006). Air-drying characteristics of tomatoes - Department of Chemical Engineering, Yildiz Technical University, 34210 Esenler, Istanbul, Turkey www.elsevier.com/locate/jfoodeng.

[12] Zafer Erbay et. al. (2010). A Review of Thin Layer Drying of Foods: Theory, Modeling, and Experimental Results.

[13] Alpha Oumar Dissa, (2007). Chéchage Convectif et solaire de la mangue (Mangifera Indica L.): Caractérisation expérimentale, modélisation et simulation du procédé Editions Universitaires Européennes.

[14] Henderson, S. M., \& Pabis, S. (1961). Grain drying theory. II: Temper- ature ef- fects on drying coefficients. Journal of Agricultural Engineering Research, 6, 169-174.

[15] Reyes A, Mahn A, Huenulaf P and González T. (2014). Tomato Dehydration in a Hybrid-Solar Dryer - Department of Chemical Engineering, University of Santiago of Chile, Av. L.

\section{B. O"Higgins 3363, Santiago, Chile.}

[16] Page, C. (1949). Factors influencing the maximum rates of air-drying of shelled corn in thin layer. Unpublished M. S. Thesis, Purdue University, Lafayette, IN.

[17] Hadi Samimi-Akhijahani et al., (2018). Accelerating drying process of tomato slices in a PV-assisted solar dryer using a sun tracking system - Department of Biosystem Engineering, Faculty of Agriculture, University of Kurdistan, Kurdistan, Iran.

[18] Crank, J. (1975). Mathematics of diffusions (2nd ed.). London: Oxford University Press.

[19] Abdulkadir Yagcioglu et al., (2007). Effective Moisture Diffusivity Estimation from Drying Data - Department of Agriculture Machinery, Faculty of Agriculture, Ege University - Bornova Izmir, Turkey.

[20] RECA, (2016). La tomate au Niger - Présentation préparée par le RECA.

[21] Alpha Oumar Dissa et al., (2009). Modelling and experimental validation of thin layer indirect solar drying of mango slices Laboratoire de Physique et de Chimie de l'Environnement (LPCE), Unité de Formation et de Recherche en Sciences Exactes et Applique'e (UFR/SEA), Universite' de Ouagadougou, Avenue Charles de Gaulle, BP 7021 Kadiogo, Burkina Faso.

[22] Vanderhofstadt Bruno et al., (2007). Guide pratique de la culture de la pomme de terre en Afrique de l'Ouest - CDE et SOC International, Belgique.

[23] L. Villa-Corrales et al., (2010). Numerical and experimental analysis of heat and moisture transfer during drying of Ataulfo mango - Centro Nacional de Investigación y Desarrollo Tecnológico, CENIDETDGEST-SEP, Prol. Av. Palmira S/N. Col. Palmira, Cuernavaca, Morelos CP 62490, Mexico.

[24] Ahouannou C., Jannot Y., Lips B., Lallemand A., (2000). Caractérisation et Modélisation du Séchage de trois Produits tropicaux: Manioc, gingembre et gombo - Sciences de Aliments, 20 (4/5).

[25] Ibrahim Doymaz et al. (2004). Drying characteristics and kinetics of okra - Department of Chemical Engineering, Yildiz Technical University - Esenler, Istanbul, Turkey.

[26] Ben Mabrouk S, Belghith A. (2000). Development of the solar crop dryers in Tunisia. World Renewable Energy congress VI; p. 2206-2211.

[27] Ian C. Kemp et al., (2001). Methods for processing experimental drying kinetics data - Drying Technology, 19 (1), 15-34.

[28] C. W. Hall, (1980). Drying and Storage of Agricultural Products - The Avi Pub. Coy Inc., Westport, Connecticut, USA.

[29] L. Remache et A. Belhamri, (2008). Modélisation du séchage par convection - Revue des Energies Renouvelables CISM'08 Oum El Bouaghi (2008) 289 - 297 Département de Mécanique, Université Larbi Ben M’Hidi, Oum El Bouaghi, Algérie - Département d'Installation, Université des Frères Mentouri, Constantine, Algérie. 
[30] P. K. Wankhade et al. (2013). Drying Characteristics of Okra slices on drying in Hot Air Dryer - Chemical Technology Department, Sant Gadge Baba Amravati University, Amravati - INDIA.

[31] S. Toure, S. Kibangu-Nkembo, (2004). Comparative study of natural solar drying of cassava, banana and mango, Renew. Energy 29 (2004) 975-990.

[32] Mohamed A. Eltawil et al., (2018). Solar PV powered mixedmode tunnel dryer for drying potato chips - Department of Agricultural Systems Engineering, College of Agricultural and Food Sciences, King Faisal University, P. O. Box 420, AlHofuf, Al-Ahsa 31982, Saudi Arabia.

[33] Zogzas N. P.; Z. B. Maroulis, (1996). Effective Moisture Diffusivity Estimation from Drying Data: a Comparison Between Various Methods of Analysis - Drying Technology, Vol. 14, (7 qnd 8): 1543-1573.
[34] Madamba, P. S., Driscoll, R. H., and Buckle, K. A. (1996). Thin-layer drying characteristics of garlic slices. Journal of Food Engineering. 29: 75-97.

[35] Giovanelli, G., Zanoni, B., Lavelli, V., \& Nani, R. (2002). Water sorption, drying and antioxidant properties of dried tomato products. Journal of Food Engineering, 52 (2), 135141.

[36] Wei Wang et al., (2018). Thermal performance of indirect forced convection solar dryer and kinetics analysis of mango School of Physical and Electronic Information, Yunnan Normal University, Kunming 650500, China.

[37] E. Barati, J. A. Esfahani (2011). A new solution approach for simultaneous heat and mass transfer during convective drying of mango - Department of Mechanical Engineering, Faculty of Engineering, Ferdowsi University of Mashhad, PO Box 91775-1111, Iran. 